九州大学学術情報リポジトリ

Kyushu University Institutional Repository

\title{
Drying Characteristics of Sweet Potato
}

Koide, Shoji

Laboratory of Agricultural Process Engineering, Faculty of Agriculture, Kyushu University

Murata, Satoshi

Laboratory of Agricultural Process Engineering, Faculty of Agriculture, Kyushu University

Uchino, Toshitaka

Laboratory of Agricultural Process Engineering, Faculty of Agriculture, Kyushu University

Amaratunga, K. S.P.

Laboratory of Agricultural Process Engineering, Faculty of Agriculture, Kyushu University

https://doi.org/10.5109/24137

出版情報：九州大学大学院農学研究院紀要. 41 (1/2)，pp. 125-132，1996-11. Kyushu University バージョン：

権利関係 : 


\title{
Drying Characteristics of Sweet Potato
}

\author{
Shoji Koide, Satoshi Murata*, Toshitaka Uchino \\ and K.S.P. Amaratunga
}

Laboratory of Agricultural Process Engineering, Faculty of Agriculture, Kyushu University, Fukuoka 812-81, Japan

(Received July 31, 1996)

\begin{abstract}
The drying test of sweet potato has been done at the air conditions of $40,50,60$, and $75^{\circ} \mathrm{C}$, in order to investigate the drying characteristics. In this study, three types of drying periods, the constant rate drying period, the first falling rate drying period, and the second falling rate drying period, was found during drying. With regards to this, three drying equations, the modified constant rate drying equation, the first falling rate drying equation, and the second falling rate drying equation were applied to the observed drying curve (moisture ratio vs. time) for each drying period respectively.

Result shows that the calculated values have a good agreement with the data. Furthermore, it revealed that drying constants in first and second falling rate drying period have Arrhenius type temperature dependency.
\end{abstract}

\section{INTRODUCTION}

Sweet potato has high moisture, and consists of a lot of functional components as $\beta$ carotene, ascorbic acid, etc. It is known as one of major functional foods and consumed by heating, boiling, frying and drying, but its drying characteristics has not been studied. This knowledge of drying characteristics is important to food engineers for determination of the details of design and use of food processing equipment.

In the past, many cereals have been measured their drying characteristics, and the dry basis moisture content during drying was reported that it reduces exponentially with time (Chittenden, D. H. and Andrew Hustrulid, 1966 as example). This fact was followed by the diffusion theory (Crank, 1956). This theory is, however, not applied to high moisture agricultural products because those have constant rate drying period during drying. Recently, limited researchers (Yoshitomi et al., 1986 as example) have been studied on the drying characteristics of high moisture agricultural product such as vegetable, fruit, and the like. It has been reported that in constant rate drying period, the moisture content not reduces constantly or exponentially with time. In other words, it holds the apparent falling rate drying phenomena, and no pronounced equation was proposed to explain its drying curve. Later, Murata et al. (1993) measured the drying characteristics of sliced radish, and proposed a new drying equation (modified constant rate drying equation), which accounts for the apparent falling rate drying phenomenon caused by the shrinkage accompanied with the moisture reduction in the constant rate drying period. They were able to fit their drying data satisfactorily by the above equation.

\footnotetext{
* Present address : 7-27-3 Miwadai, Higashi-ku, Fukuoka 811-02, Japan.
} 
Murata et al. (1995) applied the same principle for potato and good agreement was reported between calculated values and observed data .

The objectives of this study were to present the shrinkage with the moisture content reduction in the constant rate drying period, to determine the drying constants of each drying equation, and to simulate all the drying curve of sweet potato.

\section{MATERIALS AND METHOD}

\section{Materials}

Sweet potato used for this study was 'Kotobuki' which was harvested at approximately 250 percent moisture content (dry basis) at the University Farm, Faculty of Agriculture, Kyushu University, in October, 1994. The corkborer was used for cutting and the ends of the cylindrical sample were cut parallel. The sample diameter was 52.0 $\mathrm{mm}$ and the height was between 3.9 and $4.1 \mathrm{~mm}$. Two samples were used in the drying test, one was for sample weight and volume, and the other was for sample temperature during drying.

\section{Drying apparatus}

In order to investigate the drying characteristics of sweet potato, the weight, the volume and the temperature of the sample were measured during drying. Experimental apparatus is illustrated in Fig. 1. At the start of each test, two samples were placed on the

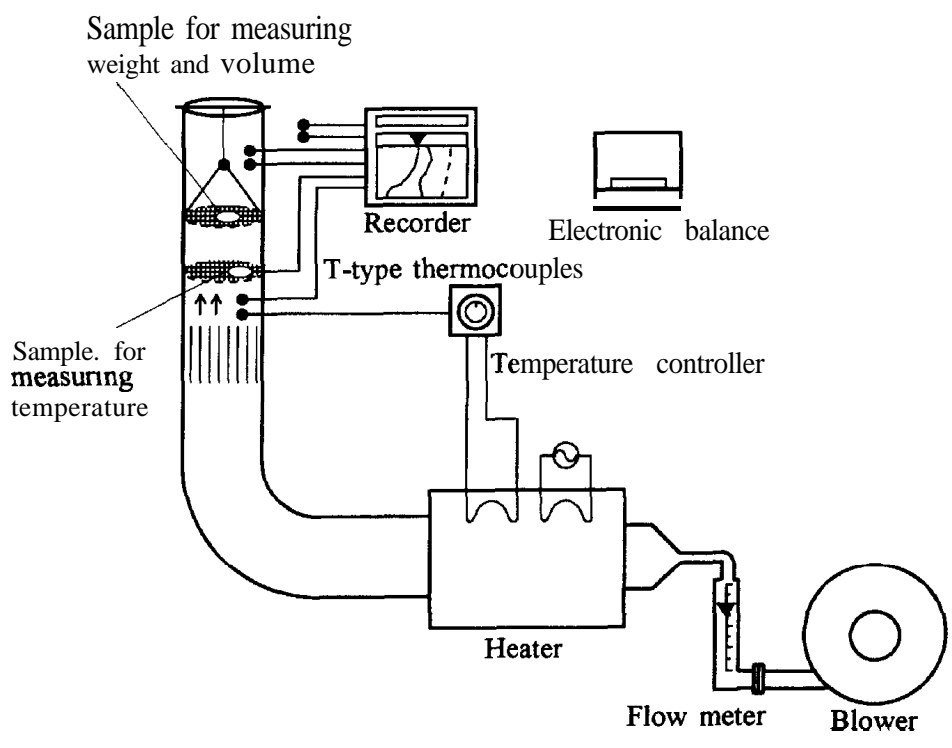

Fig. 1. Schematic diagram of experimental apparatus. 
meshes (2mm mesh). The drying test has been done at $40,50,60$, and $75^{\circ} \mathrm{C}$ of the air temperature until the weight loss of the sample was less than $10 \mathrm{mg}$ during $30 \mathrm{~min}$. The air humidity of each test was in the range of $55 \%$ to $65 \%$. During drying, the air velocity was kept at $0.25 \mathrm{~m} / \mathrm{s}$ and the air temperature was kept constant by a temperature controller (CHINO MINI-7). In the drying test, sample weight was measured using electronic balance (METTLER PK300MC) at appropriate time intervals. At the same time, sample temperature was measured by $\mathrm{T}$ type thermocouples embedded in the other sample, and recorded in a multipoint recorder (YOKOGAWA TYPE-UR Model 4156). At the end of each drying test, the final moisture content was measured by an air oven method $\left(135{ }^{\circ} \mathrm{C}\right.$ for $\left.24 \mathrm{~h}\right)$. Thus the moisture content at each time can be calculated using the final moisture content and the weight measurements.

\section{Measurement of the shrinkage of the sample during drying}

Agricultural products having high moisture shrinks during drying. Murata et al. (1993; 1995) reported theoretically and experimentally that the volume of a sample varies as a linear function of the moisture content and this shrinkage has much effect on the drying curve in the constant rate drying period. Therefore, in this drying test, to investigate the geometric shrinkage of sweet potato, the dimension of the drying sample was measured. In practice, a diameter and a height of a sample were measured instantly by a vernier caliper (MITUTOYO Accuracy: $\pm 0.025 \mathrm{~mm}$ ) at every $20 \mathrm{~min}$. Measurements were taken until the sample starts to warp.

\section{DRYING MODELS}

It has been reported from the past studies that high moisture agricultural products have three types of drying periods. First is the constant rate drying period where the sample temperature keeps constant. Second is the first falling rate drying period where

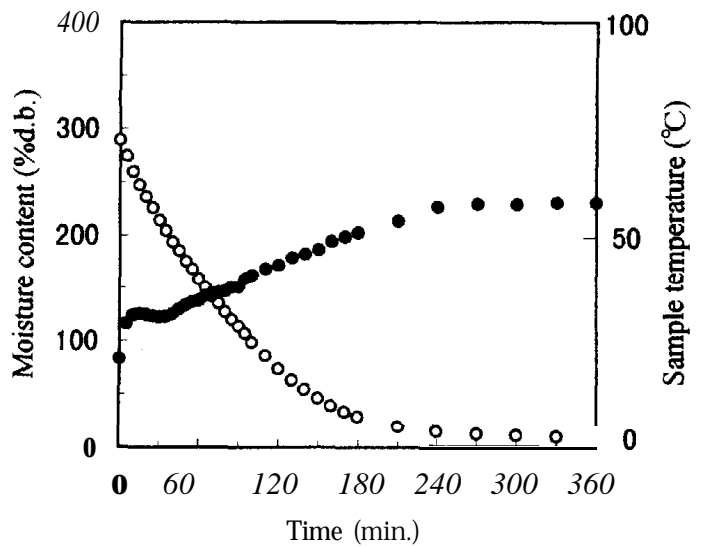

Fig. 2. Typical drying curve of sweet potato. (air temperature: 60 "C) $\mathbf{0}$, moisture content; $\mathbf{0}$, sample temperature. 
the sample temperature keeps rising with time. And the last is the second falling rate drying period where the sample temperature is nearly equal to the air temperature. A typical drying curve (moisture content vs. time) of sweet potato is shown in Fig. 2. In the early stage of drying the drying curve not follows a linear or an exponential relationship with time. This is called apparent falling rate drying by shrinkage and can be explained by the modified constant rate drying equation. Effect of shrinkage caused by reducing moisture is included in this equation.

In this study, the above equation, the first falling rate drying equation,.and the second falling rate drying equation were used to simulate the drying curve for each drying period respectively.

\section{Modified constant rate drying equation}

The modified constant rate drying equation was developed by Murata et al. (1993) for sliced radish. This equation is derived from the assumptions that the drying rate per surface area of a sample is constant, and the surface area reduces in proportion to the $2 / 3$ power of the volume. The derived equation is:

$$
\frac{d M}{d \theta}=-\alpha S_{0}^{\left(t-t^{\prime}\right)} \begin{aligned}
& (p \cdot M+q)^{2 / 3} \\
& \left(p \cdot M_{0}+q\right)^{2 / 3} / W_{d}
\end{aligned}
$$

Here, $p$ and $q$ are parameters in the follows equation (Murata et al.; 1993), which is based on the assumption that the sample volume reduces linearly with reducing moisture content.

$$
V=p \cdot M+q
$$

The symbols are as defined in the nomenclature.

\section{The first falling rate drying equation}

The first falling rate drying equation is expressed as follows.

$$
\frac{M-M_{e}}{M_{o}^{\prime}-M_{e}}=\exp \left(-k_{1} \cdot \theta^{\prime}\right)
$$

\section{The second falling rate drying equation}

The equation of second falling rate drying period was derived from the diffusion theory by Crank (1956). In this study, a plane sheet model was applied to the equation. It gives

$$
\frac{M-M_{e}}{M_{o}^{\prime \prime}-M_{e}}=\frac{8}{\pi^{2}} \times \sum_{n=1}^{\infty} \frac{1}{(2 \mathrm{n}+1)^{2}} \exp \left[\frac{-D(2 n+1)^{\prime \prime} \pi^{2} \boldsymbol{\theta}^{\prime \prime}}{\boldsymbol{\iota}^{2}}\right]
$$

The corresponding solution useful for big times is

$$
\frac{M-M_{e}}{M_{o}^{\prime \prime}-M_{e}}=\frac{8}{\pi^{2}} \exp \left(-k_{2} \cdot \theta^{\prime \prime}\right)
$$


for small times,

where

$$
\begin{aligned}
& \frac{M-M_{e}}{M_{0}^{\prime \prime}-M_{e}}=1-4 \sqrt{\frac{D \cdot \theta^{\prime \prime}}{\pi \cdot t^{2}}} \\
&=1-4 \sqrt{\frac{k_{2} \cdot \theta^{n}}{\pi^{3}}} \\
& k_{2}=\left(\pi^{2} / l^{2}\right) \cdot D
\end{aligned}
$$

\section{RESULTS AND DISCUSSION}

\section{Analysis of drying curve}

Fig. 3 shows the moisture content dependency of sample volume during drying. It revealed that the sample volume varied as a linear function of the moisture content by the analysis and graphical presentation. The derived parameters, in eqn (2) were, $\mathrm{p}=0.7635 \times 10^{-8}\left(\mathrm{~m}^{3} / \%\right.$ d.b. $), \mathrm{q}=0.4531 \times 10^{-6}\left(\mathrm{~m}^{3}\right)$.

Fig. 4 shows the comparison of the calculated drying curve and measured values for air temperature of $50{ }^{\circ} \mathrm{C}$ and $75^{\circ} \mathrm{C}$. According to this, the drying mechanism of sweet potato can be characterized as that it has three types of drying periods. Eqn (1), (3) and (4) are applied to the experimental data by a method of least squares, and a good agreement was found between the calculated values and the observed data. The experimentally determined $M^{\prime}$ o, that is, moisture content at the start of first falling drying rate period was between 121.9 and $92.8 \%$ d.b., and the $M^{\prime \prime}{ }_{0}$, that is, moisture content at the start of second falling drying rate period was between 22.4 and $13.8 \%$ d.b.. This $M^{\prime}$ 。 was close to the moisture content at which the sample started to warp.

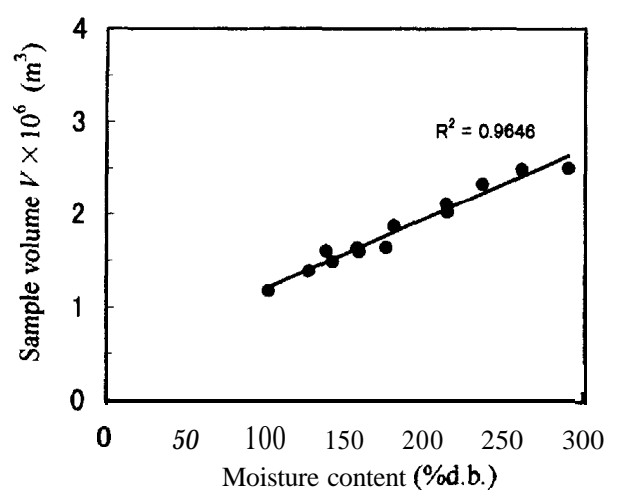

Fig. 3. Relationship between the sample volume and the moisture content. 

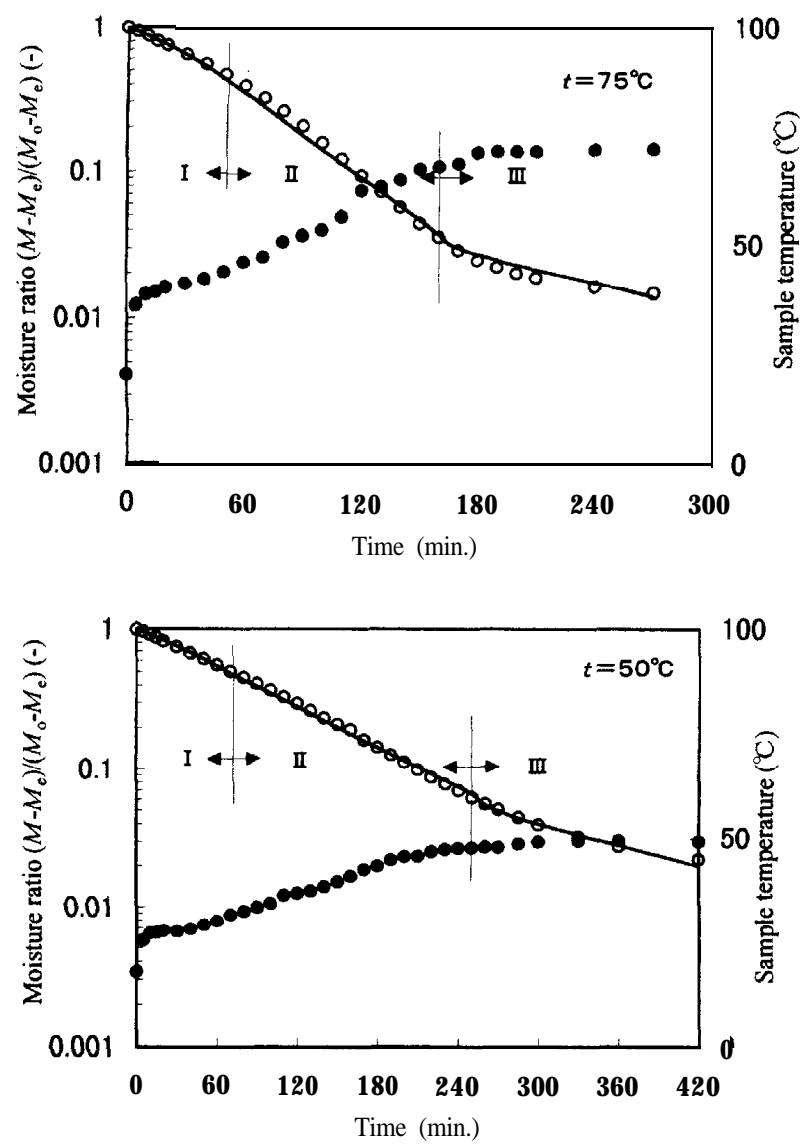

Fig. 4. A comparison of the calculated drying curve and the measured values for air temperature of 75 and 50 "C.

$\bigcirc$, moisture content; $\quad$, sample temperature.

I: constant rate drying period.

II : first falling rate drying period.

III : second falling rate drying period.

\section{Drying constant and its Arrhenius type plot}

Table 1 gives the calculated drying constants for each drying test. It revealed that the drying constant increases with increasing air temperature.

Fig. 5 indicates the Arrhenius type plot of drying constants in first and second falling rate drying period. Arrhenius type relationship is:

$$
K=d \cdot \exp \left(\frac{-f}{T}\right)
$$

Eqn (8) was fitted well to the data by a method of least squares. 
Table 1. Calculated drying constants for each test.

\begin{tabular}{cccc}
$\begin{array}{c}\text { Air temperature } \\
\left({ }^{\circ} \mathrm{C}\right)\end{array}$ & $\begin{array}{c}\alpha \\
\left(\% \mathrm{~d} . \mathrm{b} \cdot \mathrm{kg} \cdot{ }^{\circ} \mathrm{C}^{-1} \cdot \mathrm{h}^{-1} \cdot \mathrm{m}^{-1}\right)\end{array}$ & $\begin{array}{c}K_{1} \\
\left(\mathrm{~h}^{1}\right)\end{array}$ & $\begin{array}{c}K_{2} \\
\left(\mathrm{~h}^{-1}\right)\end{array}$ \\
\hline 40 & 5.4 & 0.624 & 0.301 \\
50 & 7.0 & 0.670 & 0.350 \\
60 & 12.0 & 0.975 & 0.434 \\
75 & 12.5 & 1.340 & 0.423 \\
\hline
\end{tabular}

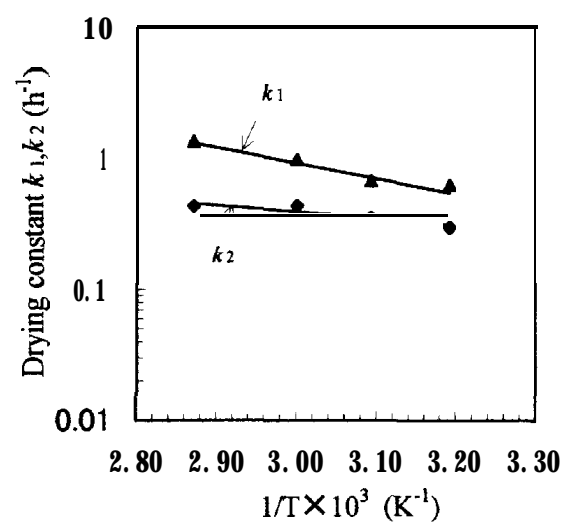

Fig. 5. Arrhenius type plot of drying constants in the first and the second falling rate drying period.

A, drying constant in the first falling rate drying period;

- drying constant in the second falling rate drying period.

\section{NOMENCLATURE}

D diffusion constant, $\mathrm{m}^{2} \cdot \mathrm{h}^{-1}$

$\mathrm{d} \quad$ defined in eqn (8), $\mathrm{h}^{-1}$

f defined in eqn (8), $\mathrm{h}^{-1}$

$k_{1} \quad$ drying constant of first falling rate drying period, $\mathrm{h}^{-1}$

$k_{2} \quad$ drying constant of second falling rate drying period, $\mathrm{h}^{1}$

$l \quad$ sample thickness, $\mathrm{m}$

$M \quad$ moisture content at time, \%d.b.

$M_{0} \quad$ initial moisture content, \%d.b.

$M_{0}{ }^{\prime} \quad$ moisture content at the start of the first falling rate drying period, \%d.b.

$M_{\text {o" }}$ " moisture content at the start of the second falling rate drying period, \%d.b.

$M_{\mathrm{e}} \quad$ equilibrium moisture content, \%d.b.

$p \quad$ defined in eqn (2), $\mathrm{m}^{3} / \%$ d.b.

$q \quad$ defined in eqn (2), $\mathrm{m}^{3}$ 
$S_{0} \quad$ surface area of a sample at initial condition, $\mathrm{m}^{2}$

$\mathrm{T}$ absolute temperature, $\mathrm{K}$

t air temperature, ${ }^{\circ} \mathrm{C}$

$t^{\prime} \quad$ sample temperature, ${ }^{\circ} \mathrm{C}$

$\mathrm{V} \quad$ sample volume, $\mathrm{m}^{3}$

$W_{\mathrm{d}} \quad$ sample dry weight, $\mathrm{kg}$

$\alpha \quad$ defined in eqn (1),\%d.b. $\cdot \mathrm{kg} \cdot{ }^{\circ} \mathrm{C}^{-1} \cdot \mathrm{h}^{-1} \cdot \mathrm{m}^{-1}$

$\theta \quad$ time, $\mathrm{h}$

$\theta^{\prime} \quad$ time (first falling rate drying period), $\mathrm{h}$

$\theta " \quad$ time (second falling rate drying period), $\mathrm{h}$

\section{ACKNOWLEDGMENTS}

The authors thank Mr. D. Imada for technical support, and Dr. K. Nakaji, Associate Prof. of University Farm, Faculty of Agriculture, Kyushu University, for supplying materials for this study.

\section{REFERENCES}

Chittenden, D. H. and A. Hustrulid 1966 Determination drying constants for shelled corn. Transactions of ASAE., 9(1): $52-55$

Crank, J. 1956 The mathematics of diffusion, Oxford university press, 42-61

Murata, S., F. Tanaka, and K. S. P. A maratunga 1994 Drying characteristics of potato (part I). J. Jpn. Soc. Agric. Machinery, $\mathbf{5 6}(4): 45-52$

Murata, S., S. Koide, and K. Miyauchi 1993 Drying characteristics of sliced radish. J. Jpn. Soc. Agric. Machinery, 55(4): 83-89

Yoshitomi, H., F. Nakao, H. Takita, and K. Suzuki 1986 Drying characteristics of tea leaves (I). J. Jpn. Soc. Agric. Machinery, 48(2): 195-202 